\title{
ASO Visual Abstract: Cytoreductive Surgery with Hyperthermic Intrathoracic Chemotherapy for Patients With Intrapleural Dissemination of Peritoneal Surface Malignancies
}

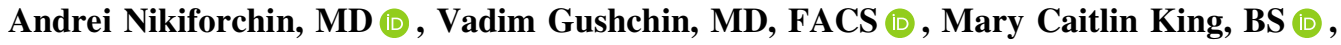

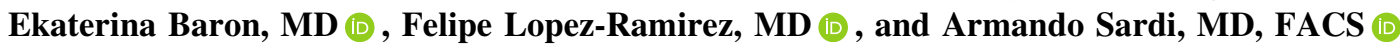 \\ Department of Surgical Oncology, The Institute for Cancer Care Mercy Medical Center, Baltimore, MD
}

Pleural dissemination of peritoneal surface malignancies worsens patient survival and quality of life (https://doi.org/ 10.1245/s10434-021-10298-2). Cytoreductive surgery with hyperthermic intrathoracic chemotherapy performed at specialized centers by experienced surgeons is a safe approach to the treatment of these patients that can improve their survival.

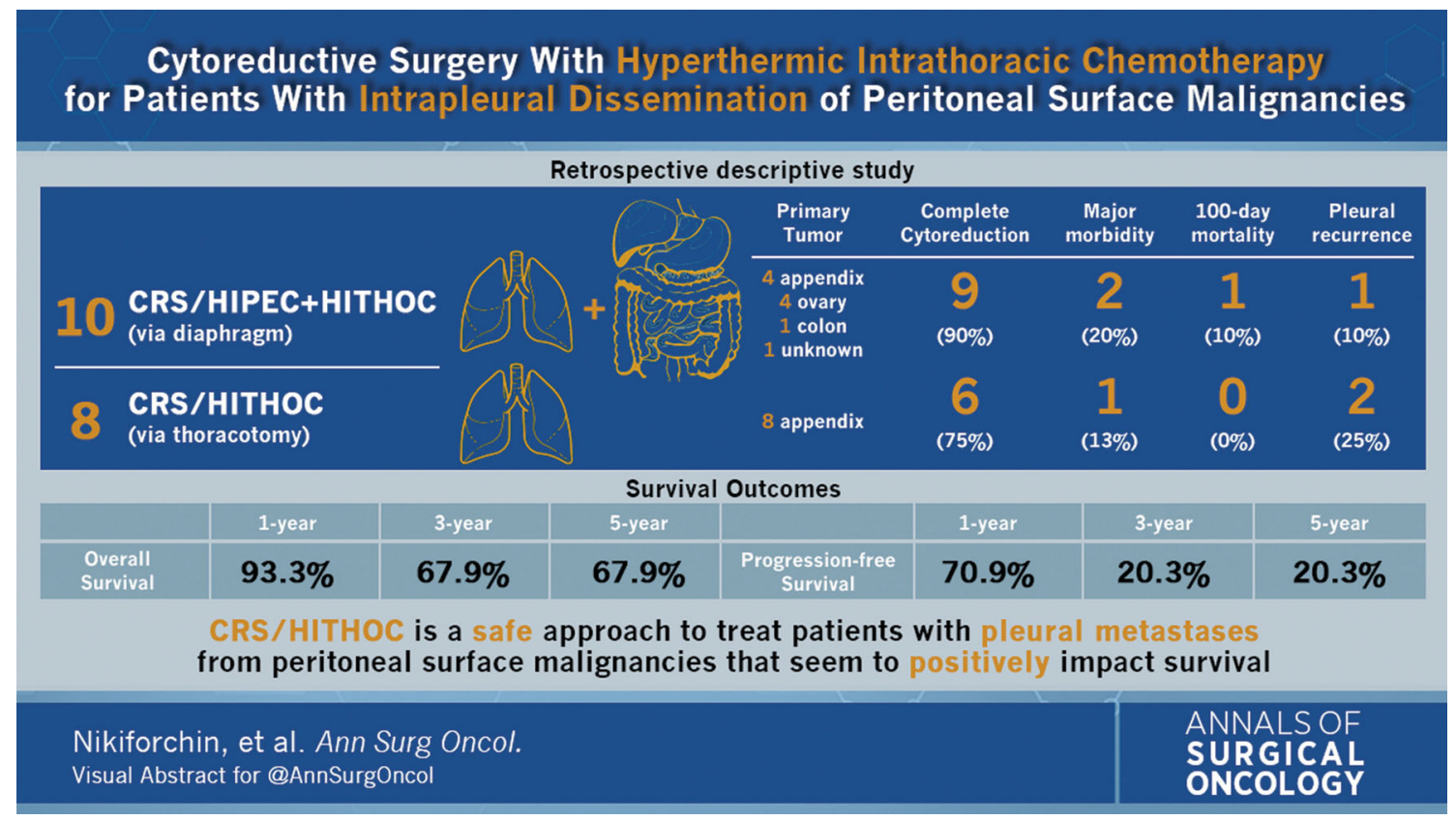

DISCLOSURE There are no conflicts of interest.

(C) Society of Surgical Oncology 2021

Published Online: 10 July 2021

A. Sardi, MD, FACS

e-mail: asardi@mdmercy.com
Publisher's Note Springer Nature remains neutral with regard to jurisdictional claims in published maps and institutional affiliations. 